Egyptian J. of Phycol. Vol. 11, 2010

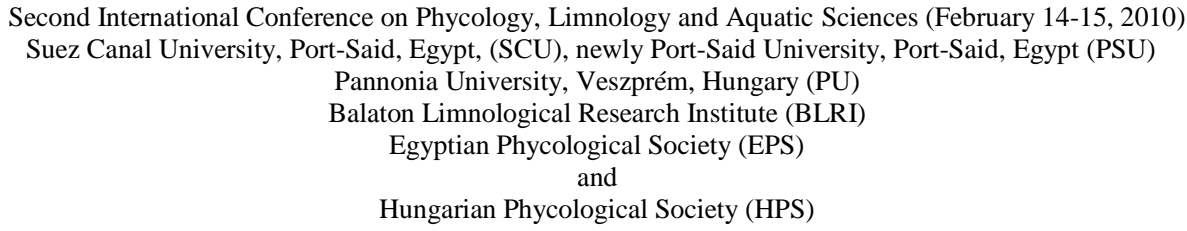

\title{
ENRICHMENT OF HETEROCYST FREQUENCY IN A NEW ISOLATE OF NOSTOC SP SAG 2306 BY 2,4-DICHLOROPHENOXYACETIC ACID AND ITS SUBSEQUENT IMPACT ON MODULATING PHOTOSYNTHESIS/RESPIRATION RATIO AND HYDROGENASES ACTIVITIES
}

\section{Fatthy Mohamed Morsy, Amany Hamid and Refat Abdel-Basset*}

Botany Department, Faculty of Science, Assiut University, Assiut, Egypt.

\begin{abstract}
Heterocysts are microaerobic specialized nitrogen fixing cells formed in some filamentous cyanobacteria and having the structural and physiological capacity to create and install internal anaerobic environment. The findings presented herein suggest that the auxin herbicide 2,4-D (2,4-dichlorophenoxyacetic acid) might be used for decreasing the culture and/or cellular oxic environment in Nostoc sp SAG 2306 that is favorable for enhancing the hydrogenases activities. This is achieved via induction and enrichment of heterocyst frequency. Treatment of the filamentous heterocyst-forming cyanobacterium Nostoc sp. SAG 2306 grown in nitrogen-deprived medium with different concentrations of 2,4-D has increased heterocyst frequency up to $19 \%$. Furthermore, 2,4-D induced heterocyst formation in the presence of combined nitrogen (nitrate) up to $90 \mu \mathrm{M}$. An increase in respiratory oxygen uptake and lowered photosynthesis/respiration (P/R) ratio, observed in 2,4-D treated Nostoc cultures, was associated with an increase in hydrogenases activities. 2,4-D caused a decrease in phycocyanin/chlorphyll $a$ ratio which

* The corresponding author: Prof. Dr. Refat Abdel-Basset,

(ISSN: 1110-8649)

Botany Department, Faculty of Science, Assiut University,

Assiut 71516, Egypt.

Phone: +2-88-2412297 Fax: +2-088-2342708

E-mail: rbasset@aun.edu.eg
\end{abstract}


was associated with a decrease in photosynthetic oxygen evolution suggesting that the decrease in phycocyanins which are a major component of phycobilisomes, the lightharvesting complex of photosystem II in cyanobacteria, due to 2,4-D treatment has a negative impact in oxygen evolution and a positive impact on hydrogenases activities.

Lowered values of phycocyanin/chlorphyll $a$ ratio, decreased oxygen evolution, photosynthesis/respiration $(\mathrm{P} / \mathrm{R})$ ratio with enhanced respiration and heterocyst formation all have been induced by 2,4-D cooperated to install anaerobiosis for hydrogen metabolism.

Key words: cyanobacterium; heterocyst; hyrdogenase; Nostoc; 2,4-D

\section{Introduction}

Heterocysts are specialized nitrogen fixing cells formed in some filamentous cyanobacteria under nitrogen starvation where some vegetative cells differentiate into heterocysts (Wolk, 1996; Zhang et al., 2006). Once a heterocyst has formed, it cannot revert to a vegetative cell (Kulasooriya and Fay, 1974). In cyanobacteria whose heterocysts are intercalary such as Nostoc and Anabaena, the differentiated heterocysts are evenly spaced along the filament to form a semiregular pattern (Yoon and Golden, 1998; 2001). As the filament grows and the number of vegetative cells between heterocysts increases, single vegetative cell midway between two heterocysts develop into a new one, thus preserving the semi-regular pattern of differentiated cells (Wolk, 1996; Golden and Yoon, 2003). The differentiation of cyanobacterial vegetative cells into heterocysts include global change in gene expression (Wolk et al., 1994; Adams, 2000; Wolk, 2000) including that of nitrogenase and other proteins involved in nitrogen fixation (Böhme, 1998; Herrero et al., 2001; Meeks and Elhai, 2002; Golden and Yoon, 2003). Heterocysts do not carry out photosynthesis since they lack RuBP carboxylase activity as well as PSII and phycobilisomes, the light harvesting complex of cyanobacterial vegetative cells (Donze et al., 1971; Codd et al., 1980; Fay, 1992; Wolk et al., 1994). In addition, they are protected from the external oxygen by a glycolipid layer in its cell wall which reduces the permeation of oxygen into the cell (Nicolaisen et al., 2009). Furthermore, 
heterocysts produce myoglobulin for scavenging any remaining oxygen inside the cell (Potts et al., 1992). Consequently, heterocysts form a microaerobic environment that is compulsory for nitrogenases and hydrogenases activity. The ammonia formed by nitrogen fixation is then incorporated into glutamate to form glutamine which is transported to the vegetative cells from heterocysts, and in return, carbohydrates, believed to be sucrose (Curatti et al., 2002) is transported from the vegetative cells to heterocysts.

As a byproduct of nitrogen fixation in heterocysts, hydrogen gas is produced. One molecule of hydrogen gas is produced for each fixed molecule of nitrogen. An uptake hydrogenase is particularly expressed in heterocysts (Houchins and Burris, 1981; Houchins, 1984; Papen et al., 1986; Carrasco et al., 1995) that catalyzes the consumption of molecular hydrogen through its oxidation into protons and electrons (Lambert and Smith, 1981; Houchins, 1984; Tamagnini et al., 2000, Tamagnini et al., 2002) and ATP to be reinvolved in cellular energetics and proton pools. Uptake hydrogenase is localized in the thylakoid membranes of heterocysts, where it transfers electrons from hydrogen for the reduction of oxygen via the respiratory chain in a reaction known as oxyhydrogenation or Knallgas reaction (Dutta et al., 2005). A knockout mutation of the uptake hydrogenase has increased the hydrogen productivity in heterocysts (Yoshino et al., 2007). A bidirectional hydrogenase with the capacity to both taking up and producing hydrogen is also involved in hydrogen metabolism of cyanobacteria (Houchins, 1984; Flores and Herrero, 1994; Bergman et al., 1997; Appel and Schulz , 1998; Hansel and Lindblad, 1998; Lindblad, 1999; Appel et al., 2000; Tamagnini et al., 2002; Tsygankov, 2007). The bidirectional hydrogenase is associated with the cytoplasmic membrane and likely functions as an electron acceptor from both $\mathrm{NADH}$ and $\mathrm{H}_{2}$ (Dutta et al., 2005) but its biological role is poorly understood (Boison $\boldsymbol{e t}$ al., 1999). It may release excess reducing power in anaerobic conditions thus acting as an electron valve for the disposal of low potential electrons generated at the onset of illumination (Stal and Moezelaar, 1997) or during periods of adaptation to high light intensities (Appel et al., 2000) although it is not a universal enzyme. Nevertheless, the physiological 
implications of hydrogenases are altogether debatable. Unlike uptake hydrogenase, the bidirectional hydrogenase is helpful in hydrogen production (Dutta et al., 2005) and its function suggested to be independent of nitrogen fixation (Tamagnini et al., 2002) because the biosynthesis of nitrogenase was not a prerequisite for the bidirectional hydrogenase biosynthesis and hydrogen evolution in several unicellular cyanobacterial strains (Howarth and Codd, 1985).

Oxygen is a powerful inhibitor to hydrogenases activities. The enrichment of heterocysts increases the number of the microaerobic cells on the one side and decreases net oxygen productivity in the culture as a whole on the other side that can be a route for increasing the hydrogen gas productivity in cyanobacteria. In this study, both uptake and bidirectional hydrogenases have been characterized in the heterocyst enriched Nostoc sp. Since the role of 2,4-D in enhancing heterocyst formation has been recorded (Tiwari et al., 1981), serial concentrations of 2,4-D were added to nitrate deprived medium $\left(\mathrm{BG} 11_{0}\right)$. The impact of 2,4-D on heterocyst frequency and its consequences on photosynthesis and hydrogenases activities in a new isolate of Nostoc sp are studied.

\section{Materials and Methods}

\section{Growth conditions and treatments of Nostoc}

The filamentous cyanobacterium Nostoc sp SAG 2306 (newly deposited strain in Sammlung von Algenkulturen der Universität Göttingen) was locally isolated from a clay soil sample from the agriculture farm, Assiut University, Egypt and identified by SAG in a collaborative work (submitted). Nostoc was grown as batch culture in BG11 nutritive media (Rippka and Herdman, 1992) at ambient temperature of $25^{\circ} \mathrm{C} \pm 1$ in a growth chamber (Forma Scientific, USA) in which continuous illumination preformed by 2 fluorescent tubes (day light) giving irradiance of about $13.5 \mu \mathrm{E} \cdot \mathrm{m}^{-2} \cdot \mathrm{s}^{-1}$ at the surface of the culture vessels. Since it is widely known that combined nitrogen inhibits heterocyst formation, Nostoc was grown in $\mathrm{BG} 11_{0}$ medium that is a regular BG11 but deprived of combined 
nitrogen In concert with the aim of this work, the $\mathrm{BG1} 1_{0}$ cells has been treated with 2,4-D in concentrations $\left(0,2.5,5,10,20,30,50\right.$ and $\left.100 \mu \mathrm{g} \cdot \mathrm{ml}^{-1}\right)$ to induce and enrich heterocyst frequency of Nostoc. However, undifferentiated filaments were used as inoculum in all experiments.

\section{Growth and analytical assessments:}

Growth was daily assessed by three parameters: optical density at $750 \mathrm{~nm}$, chlorophyll $a(\operatorname{chl} a)$ contents and dry mass. Chl $a$ was dark-extracted under cooling in $100 \%$ methanol for $24 \mathrm{~h}$, clarified by centrifugation under cooling $\left(4^{\circ} \mathrm{C}\right)$ at $7000 \times g$ for $15 \mathrm{~min}$ and quantified spectrophotometrically according to the equations of Holden (1976). For dry mass assessment, aliquots of algal suspension (e.g. $25 \mathrm{ml}$ ) were filtered above a pre-weighed glass fiber filter, washed three times with distilled water, oven-dried overnight at $80^{\circ} \mathrm{C}$ and reweighed periodically up to constancy. For heterocyst frequency determination, the cyanobacterium was photographed, hetrocysts and vegetative cells were counted and heterocyst frequency was calculated according to Troshina $\boldsymbol{e t}$ al. (1996). Phycocyanin was determined as described by Tchernov $\boldsymbol{e t}$ al. (1999). Protein concentration was determined by CBB G-250 dye binding method described by Bradford (1976) using bovine serum albumin (BSA) as a standard protein.

\section{Photosynthesis and respiration:}

Photosynthetic oxygen evolution was measured using a Clark type oxygen electrode computerized to an oxygen monitoring system (OMS, Hansatech Instruments Inc., donation from Alexander von Humboldt foundation to R. Abdel-Basset). $\mathrm{O}_{2}$ evolution was measured in actinic light $\left(44.5 \mu \mathrm{E} \cdot \mathrm{m}^{-2} . \mathrm{s}^{-1}\right.$ at the surface of the cell) passed through a red optical filter. All measurements were performed at $25 \pm 1{ }^{\circ} \mathrm{C}$ stabilized by a circulating water bath. Respiratory $\mathrm{O}_{2}$ uptake was measured using the same above-mentioned Clark electrode and oxygen monitoring system at identical conditions but in the dark. photosystem I (PSI) activity was followed as described earlier (Abdel-Basset and Bader, 2008). 


\section{Hydrogenases assays:}

Uptake hydrogenase was assayed by the hydrogen dependent reduction of methylene blue according to Colbeau et al. (1980). Intact cyanobacterial cells containing 3-4 $\mu \mathrm{g}$ chlorophyll (varied according to the treatment) were centrifuged, concentrated to $0.2 \mathrm{ml}$ and used in assays. The reaction assay mixtures were flushed with hydrogen gas for one minute and the decrease in absorbance of methylene blue at $570 \mathrm{~nm}$ was followed periodically using a spectrophotometer (Spectronic 20D, Milton Roy company) at ambient temperature. The hydrogen evolution activity of the biodirectional hydrogenase was monitored using assay mixtures similar to those used by $\mathbf{Y u}$ and Wolin (1969). The assay depends on dithionite reduced methyl viologen as the electron donor after nitrogen flushing. The decrease in absorbance at $578 \mathrm{~nm}$ was followed periodically using a spectrophotometer at ambient temperature.

\section{Characterization of hydrogenases:}

Characterization of the hydrogenases enzymes was carried out using cells grown in nitrate deprived medium $\left(\mathrm{BG} 11_{0}\right)$ which is necessary to induce heterocyst formation.

\section{Enzyme Kinetics:}

$\mathrm{K}_{\mathrm{m}}$ value of hydrogenases for methyl viologen in the hydrogen evolution activity and for methylene blue in the hydrogen uptake activity were determined using Lineweaver-Burk plots of various concentrations of the respective dyes against hydrogenases activities. Characterization included also factors affecting enzymes activity. Temperature ranging from 20 to $50{ }^{\circ} \mathrm{C}$ was applied. The $\mathrm{pH}$ range from 5.4 to 9.4 using respective buffers $(50 \mathrm{mM}$ citrate-phosphate buffer for the $\mathrm{pH}$ range from 5.4 to $6.6,50 \mathrm{mM}$ tris- $\mathrm{HCl}$ buffer for the $\mathrm{pH}$ range from 7 to 9 and $50 \mathrm{mM}$ CHES-NaOH buffer for the $\mathrm{pH}$ range from 9 to 9.4). Characterization included, in addition, photosynthetic effectors DCMU [3-(3,4dichlorophenyl)-1,1-dimethylurea] and $\mathrm{CCCP}$ [carbonyl cyanide mchlorophenylhydrazone].

Egyptian J. of Phycol. Vol. 11, $2010 \quad 32$ - 


\section{Results}

\section{Effect of 2,4-D treatment on growth of Nostoc sp:}

Under nitrogen starvation, the cyanobacterium Nostoc sp SAG 2306 showed high fragmentation (data not shown) and lower chl a/ dry mass (Fig 1A) as heterocysts were formed and enriched at the expense of chl $a$ contained in vegetative cells. In control cultures (BG11), chl a content of Nostoc sp. was 12 $\mu \mathrm{g} . \mathrm{mg}^{-1}$ dry weight whilst in BG1 $1_{0}$ it exhibited only $7.8 \mu \mathrm{g} \cdot \mathrm{mg}^{-1}$ dry weight. 2,4D slightly enhanced the growth of Nostoc sp. as revealed by optical density and dry mass (Fig. 1A). In contrast, 2,4-D did not significantly affect chl $a$ content per culture volume (Fig 1A). However, the chl a/dry mass decreased with increasing 2,4-D concentration in the culture medium (Fig. 1A). 2,4-D treatment decreased the phycocyanin/ chl a ratio in Nostoc sp. grown in nitrogen deprived medium (Fig 1B).

\section{Effect of 2,4-D treatment on heterocyst frequency of Nostoc:}

2,4-D induced and enriched heterocysts in Nostoc sp. (Fig. 2A). Figure (2 B) shows heterocyst free filaments in BG11 (BI), 2,4-D heterocyst containing fragments (BII), two or more adjacent heterocysts appear occasionally at 100 $\mu \mathrm{g} . \mathrm{ml}^{-1}$ 2,4-D (BIII) and detached (BIV). Table (1) presents a detailed follow up of heterocyst formation in Nostoc. Heterocysts started to appear at the $6^{\text {th }}$ day after cells grown in nitrate replete (BG11) medium were transferred into nitratedeprived medium $\left(\mathrm{BG} 11_{\mathrm{R}}\right)$. Transferring the inoculum cells from BG11 simultaneously transfers into the new culture of $\mathrm{BG} 11_{0}$ residual nitrate accounting to only $2 \%$ that in $\mathrm{BG} 11$, referred to as $\mathrm{BG} 11_{\mathrm{R}}$. Upon removing this residue by washing the inoculum cells with $\mathrm{BG} 11_{0}$ before inoculation and the medium become completely free from any combined nitrogen (BG11 $1_{0}$ culture), heterocysts appeared promptly earlier after only $24 \mathrm{~h}$ of cultivation (Table 1 ).

Collectively, then, full nitrogen strength (BG11 medium) absolutely inhibited heterocyst formation; $\mathrm{BG} 11_{\mathrm{R}}$ (deprived of nitrate but containing residual combined nitrogen) induced the appearance of heterocysts at the $6^{\text {th }}$ day, BG11 $1_{0}$ 
A

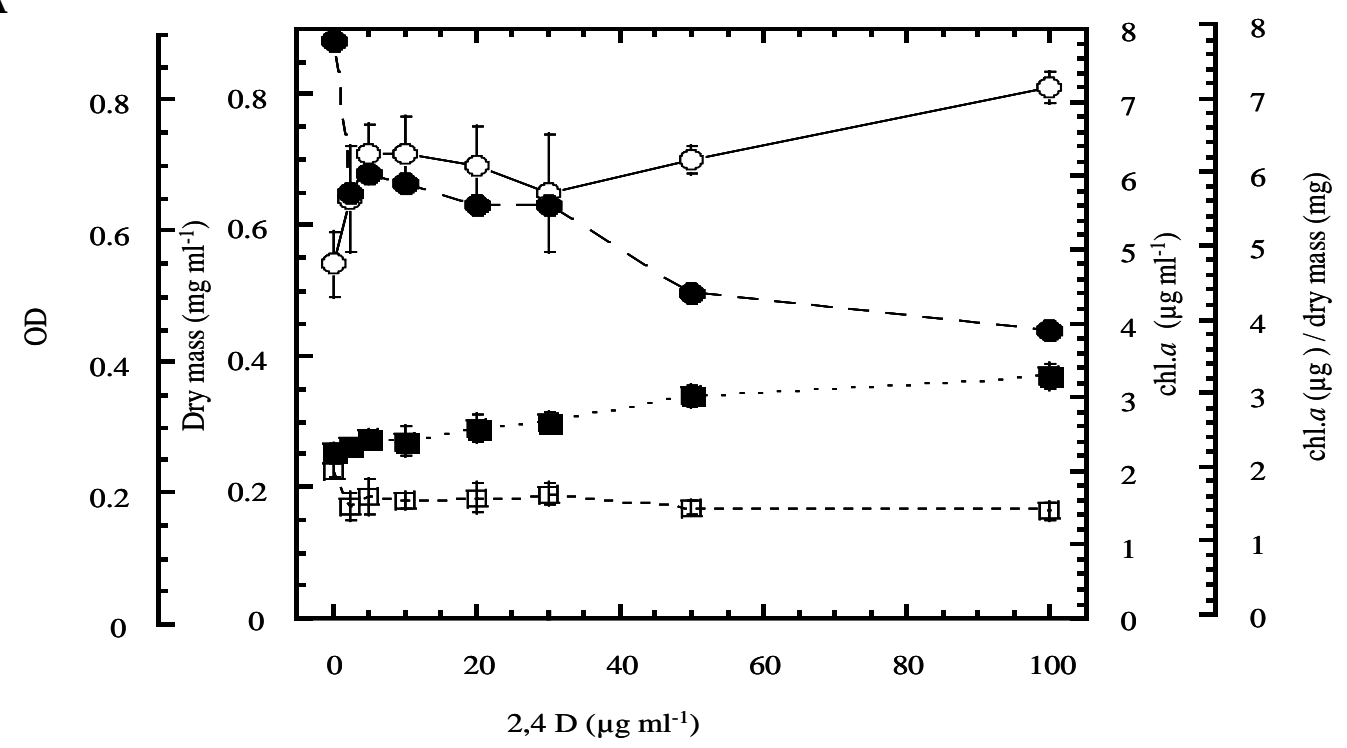

B

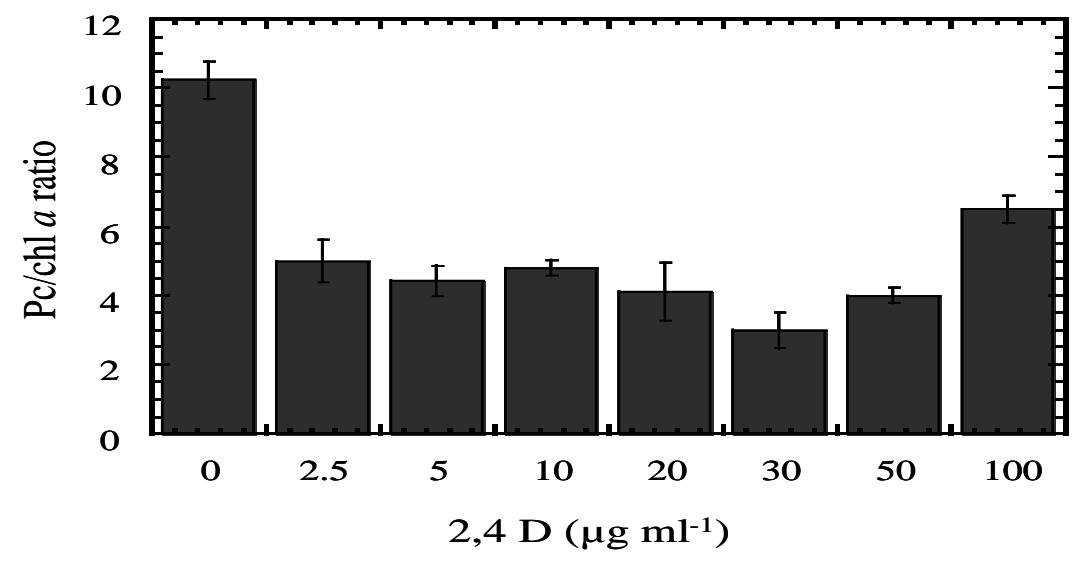

Figure (1): Effect of 2,4-D on growth, chl $a /$ dry mass ratio and PC/chl $a$ ratio of Nostoc sp. SAG 2306 grown in BG11 ${ }_{0}$ medium. Growth of Nostoc (panel A) was assessed with optical density (open circles), dry mass (closed squares) and chl $a$ (open squares). The chl $a /$ dry mass ratio (closed circles) was calculated using the mean values of both parameters. Phycocyanin content was measured as described in Materials and Methods and the PC/chl $a$ ratio (panel B) were calculated at each concentration of 2,4-D-treated Nostoc sp. culture. Experiments were repeated three times and mean values and standard errors are shown. 

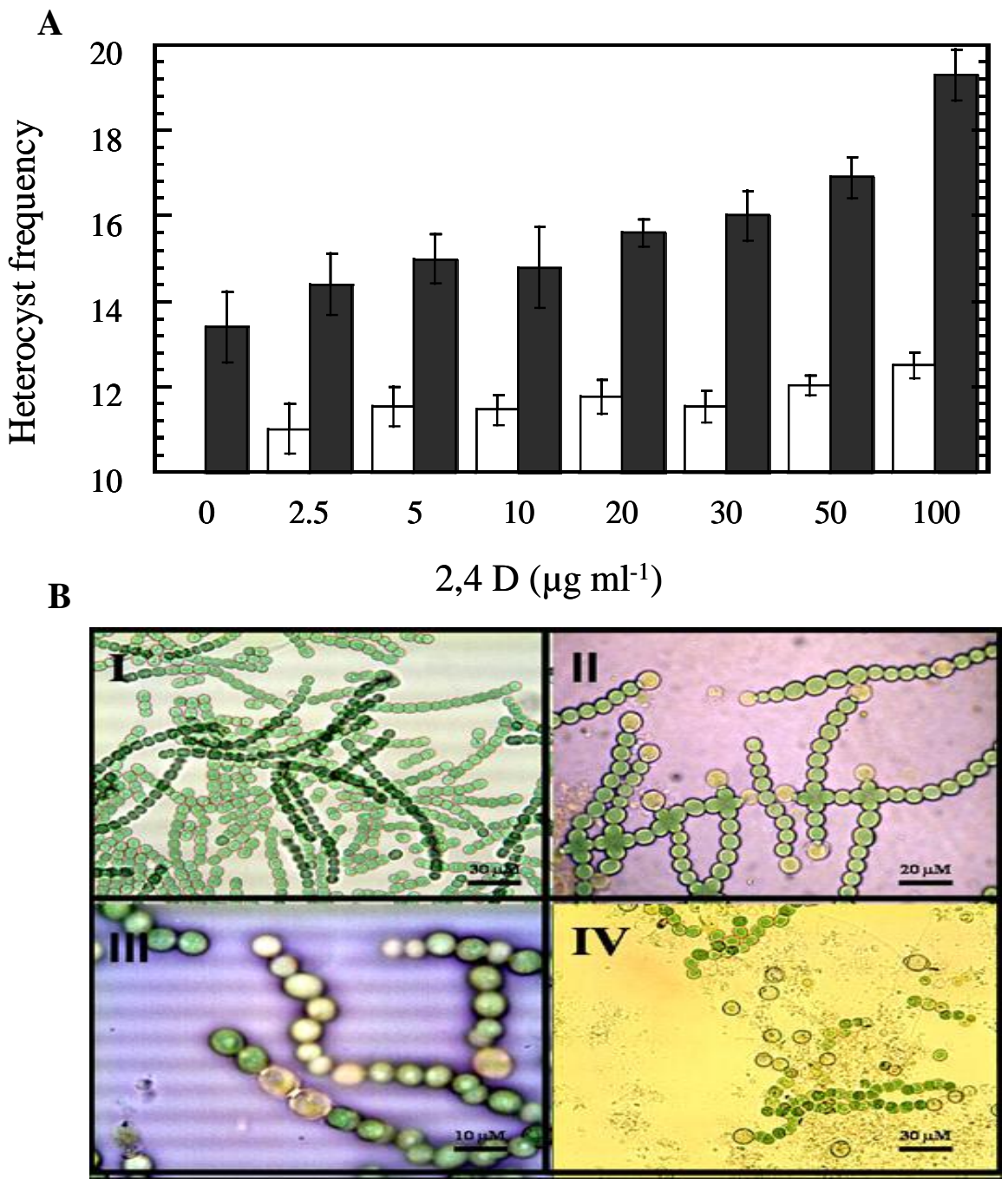

Figure (2): Effect of 2,4-D on heterocyst frequency of Nostoc sp. SAG 2306 grown in BG11 $_{0}$ medium (panel A). Hetrocyst frequency was followed daily and the data shown for the $3^{\text {rd }}$ day (white columns) and the $7^{\text {th }}$ day (black columns) of Nostoc sp. grown on BG11 $_{0}$ treated with different concentration of 2,4-D. Experiments were repeated three times and mean values and standard errors are shown. Light microscope photographs

of Nostoc sp.(panel B). A photgraph of the cyanobacterium grown in nitrogen enriched medium (BG11) showing no heterocysts (photo I). The photograph II and III

show Nostoc sp. grown in nitrogen deprived medium (BG11 $)$ and that grown in BG11 ${ }_{0}$ treated with $100 \mu \mathrm{M} 2,4-\mathrm{D}$ at the $7^{\text {th }}$ day of growth respectively. Nostoc culture grown in $\mathrm{BG11}_{0}$ treated or not with 2,4-D showed detached heterocysts at late growth phase (Photo IV). 
culture (completely deprived of nitrate and residuals) accelerated heterocyst formation promptly at day 1 . The addition of a definite concentration of $60 \mu \mathrm{M}$ nitrogen (in the nitrate form) to the $\mathrm{BG} 11_{0}$ culture simulated an effect similar to that of $\mathrm{BG} 11_{\mathrm{R}}$ since it delayed the appearance of heterocysts to day 6 . The same timing of heterocysts appearance might indicate both concentrations are similar. i.e. residual combined nitrogen is equivalent to $60 \mu \mathrm{M}$ nitrogen at least in effect if not in concentration. The inclusion of the 2,4-D accelerated the formation of heterocysts and increased its frequency in $\mathrm{BG} 11_{\mathrm{R}}$ medium. In $\mathrm{BG} 11_{0}$ culture, however, $100 \mu \mathrm{g} \cdot \mathrm{ml}^{-1}$ of 2,4-D did not exert a remarkably enhancing effect on heterocyst formation and/or frequency because any inhibitory or delaying effect ascribed to combined nitrogen was completely not existing (heterocysts actually appeared by the first day).

In another approach trying to find out the concentration of nitrate that 2,4$\mathrm{D}$ can overcome its inhibitory effect on heterocyst formation, concentrations of 15, 30, 60, 90 or $120 \mu \mathrm{M}$ nitrogen was combined with $100 \mu \mathrm{g} \cdot \mathrm{ml}^{-1}$ 2,4-D. In this case, $15 \mu \mathrm{M}$ nitrogen did not affect heterocyst formation and was similar to BG1 $1_{0}$ culture while $30 \mu \mathrm{M}$ nitrogen delayed it to the $3^{\text {rd }}$ day that has been overcome by $2,4-\mathrm{D}$ at day 2 . At a concentration of $60 \mu \mathrm{M}$ nitrogen heterocyst formation was delayed to day 6 but enhanced by 2,4-D at day 2. Therefore, as the concentrations of combined nitrogen increased its delaying effect was more pronounced and the stimulatory ability of 2,4-D becomes more pronounced. However, the concentration of $120 \mu \mathrm{M}$ nitrogen inhibited heterocyst formations and the addition of 2,4-D failed to overcome this inhibition (Table 1) i.e. the stimulatory ability on heterocyst formation of 2,4-D to overcome the inhibitory effect is up to certain limits (below $120 \mu \mathrm{M}$ nitrogen in this case).

Characterization and Kinetics of Uptake and Bidirectional Hydrogenases in Nostoc sp. grown in BG11

Under ambient culture conditions of the cyanobacterium in $\mathrm{BG} 11_{0}$, the uptake hydrogenases activity of Nostoc sp. was higher than its evolution hydrogenase activity with all enzyme (intact cyanobacterium) concentrations used (data not shown).

Egyptian J. of Phycol. Vol. 11, 2010

- 36 - 
Table (1): Induction and enhancement of heterocyst formation of Nostoc sp SAG 2306 by $100 \mu \mathrm{g} \cdot \mathrm{ml}^{-1} 2,4-\mathrm{D}$, in the presence or absence of various levels of combined nitrogen (Nitrate form).

\begin{tabular}{|c|c|c|c|c|c|c|c|c|c|c|c|}
\hline \multirow[t]{2}{*}{ Treatment } & \multicolumn{11}{|c|}{ Days } \\
\hline & 0 & 1 & 2 & 3 & 4 & 5 & 6 & 7 & 8 & 9 & 10 \\
\hline BG11 & & & & & & & & & & & \\
\hline $\mathrm{BG} 11_{\mathrm{R}}$ & & & & & & & 13 & 13 & 13.5 & 11 & 9 \\
\hline $\mathrm{BG} 11_{0}$ & & 11 & 11 & 9 & 6 & 6 & 5 & 6 & 5 & 4 & $\mathrm{D}$ \\
\hline $\mathrm{BG} 11_{0}^{+}$ & & 13 & 14 & 11 & 9 & 7 & 7 & 7 & $\downarrow$ & $\downarrow$ & $\mathrm{D}$ \\
\hline $\mathrm{BG} 11_{15}$ & & 9 & 10 & 6 & 5 & 5 & 5 & 6 & $\downarrow$ & $\downarrow$ & D \\
\hline $\mathrm{BG} 11_{15}{ }^{+}$ & & 12 & 12 & 13 & 10 & 6 & 6 & 5 & $\downarrow$ & $\downarrow$ & $\mathrm{D}$ \\
\hline $\mathrm{BG} 11_{30}$ & & & & 6 & 7 & 6 & 5 & 4 & $\downarrow$ & $\downarrow$ & $\mathrm{D}$ \\
\hline $\mathrm{BG} 11_{30}{ }^{+}$ & & & 10 & 10 & 9 & 9 & 6 & 6 & $\downarrow$ & $\downarrow$ & $\mathrm{D}$ \\
\hline BG $11_{60}$ & & & & & & & 13 & 13.7 & 15 & 15 & 13 \\
\hline $\mathrm{BG} 11_{60}^{+}$ & & & 13 & 15 & 17.3 & 18.8 & 20 & 19.7 & 19 & 15 & 14 \\
\hline $\mathrm{BG}_{1} 1_{90}$ & & & & & & & & & & & \\
\hline BG1 $1_{90}{ }^{+}$ & & & & & & & & & 9 & 10 & 10 \\
\hline $\mathrm{BG} 11_{120}$ & & & & & & & & & & & \\
\hline $\mathrm{BG} 11_{120}{ }^{+}$ & & & & & & & & & & & \\
\hline
\end{tabular}

* Heterocyst frequency was calculated as percentage relative to vegetative cells and the average of two experiments are presented. BG11 is the control medium containing $17.6 \mathrm{mM}$ nitrate (3 mM nitrogen), BG11 $_{\mathrm{R}}$ is nitrate deprived medium but still contains residual of combined nitrogen representing only $2 \%$ that of BG11 transferred with the inoculum cells, BG11 $_{0}$ is absolutely free from any combined nitrogen; nitrate or residual. The digits subscripted to BG11 represent the concentration of combined nitrogen $(\mu \mathrm{M})$ added to zero culture in the form of nitrate, $\left(^{+}\right)$indicates inclusion of $100 \mu \mathrm{g} . \mathrm{ml}^{-1}$ 2,4-D in culture medium, $\downarrow$ refers to declined heterocyst frequency to trivial numbers due to detachment of which from the filaments, $D$ is detached leaving the filaments heterocyst free. 
The uptake hydrogenase activity of Nostoc sp. was almost double that of the hydrogen evolution activity of the bidirectional enzyme. The $\mathrm{Km}$ value of bidirectional hydrogenase for methylviologen was $0.24 \mathrm{mM}$ MV(Fig. 3A) while that of uptake hydrogenase for methylene blue was $28.9 \mu \mathrm{M} \mathrm{MB}$ (Fig. 3B). The optimum $\mathrm{pH}$ value (Fig. 4A) for hydrogenases evolution/uptake ratio by the cyanobacterium is slightly acidic ( $\mathrm{pH}$ 6.6). The optimum temperature range (Fig. 4B) for the uptake hydrogenase was $35-40{ }^{\circ} \mathrm{C}$ while that for bidirectional hydrogenase was $30-35^{\circ} \mathrm{C}$.
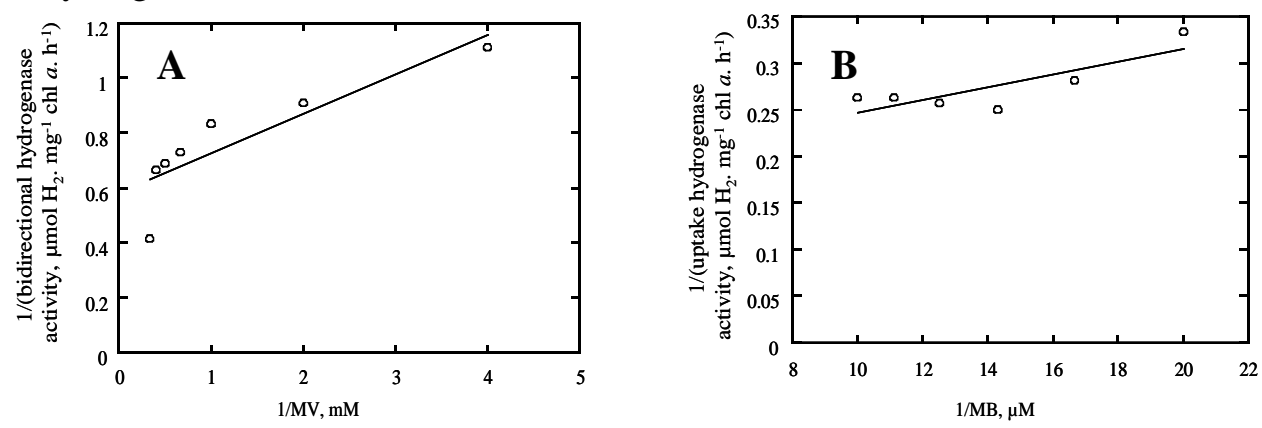

Fig. 3: Lineweaver-Burk plots for determination of the $\mathrm{Km}$ values of Bidirectional (panel A) and uptake (panel B) hydrogenases.
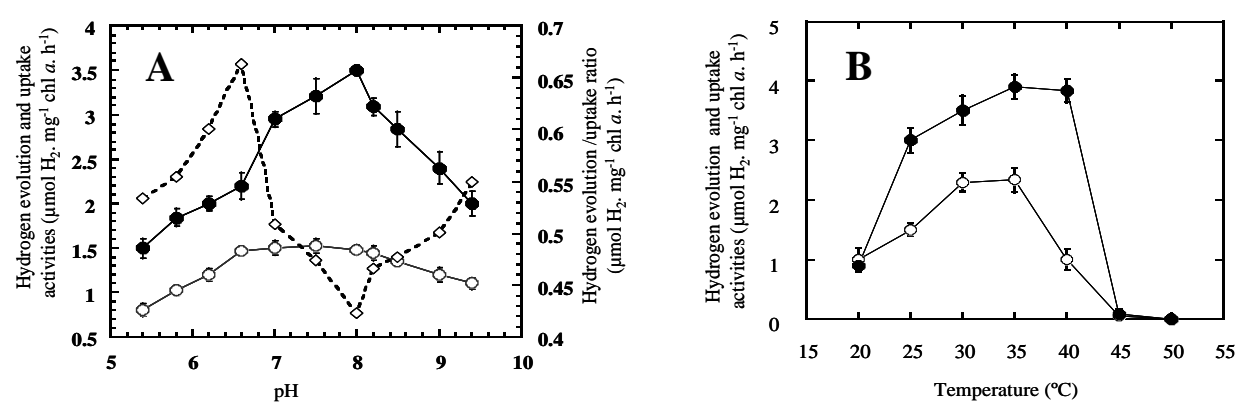

Figure (4): Effect of pH and temperature on hydrogen evolution and uptake activities of Nostoc. Effect of pH (panel A) on the hydrogen evolution (open circles) and uptake (closed circles) activities of 7 day old culture of Nostoc grown in BG11 medium were measured at various $\mathrm{pH}$ values at ambient temperature. The hydrogen evolution/uptake ratios (open cubic) were calculated using the mean values of both activities at each pH. Effect of temperature (panel B) on hydrogen evolution (open circles) and uptake (closed circles) activities of Nostoc was measured on potassium phosphate buffer (pH 7 at ambient temperature). Experiments were repeated three times and mean values and standard errors are shown. 
A very sharp decrease in uptake and bidirectional hydrogenase activities was observed at $45{ }^{\circ} \mathrm{C}$ (close to zero value) and at $50{ }^{\circ} \mathrm{C}$ both uptake and bidirectional hydrogenase activities were zero. The hydrogenase evolution activity of bidirectional hydrogenase increased upon treatments with uncoupler CCCP (Fig. 5A) while the uptake hydrogenase activity decreased. DCMU (specific inhibitor of the electron flow from PSII) increased both hydrogenase evolution and uptake activities (Fig. 5B).
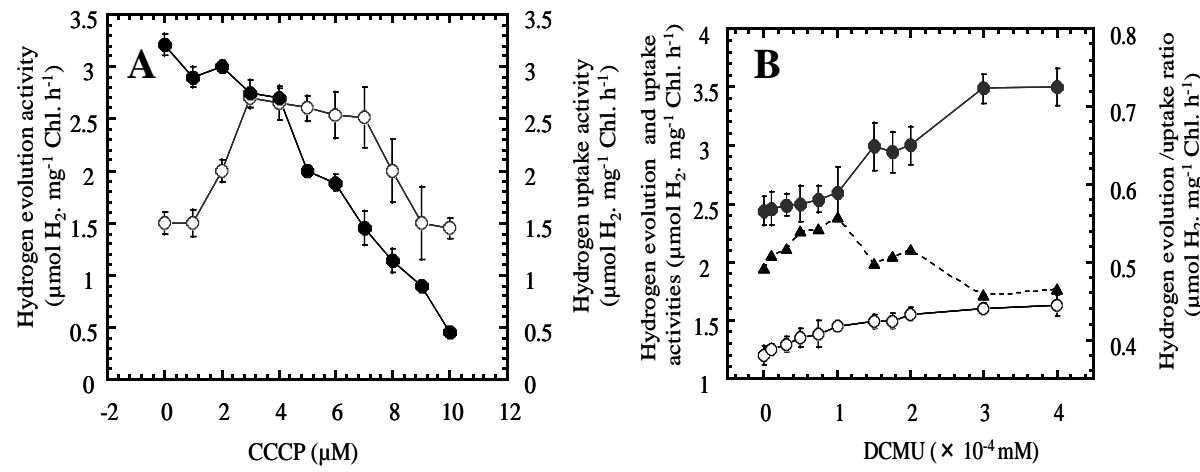

Figure (5): Effect of uncoupler CCCP and the PSII inhibitor DCMU on hydrogen evolution and uptake activities of Nostoc sp. The effect of CCCP on hydrogen evolution and uptake activities (panel A) was conducted on 7 day old cells of Nostoc

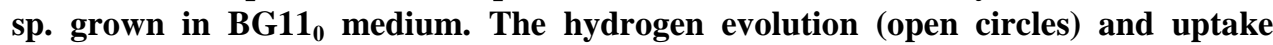
(closed circles) activities were measured as described in Materials and Methods in presence of various concentrations of $(0-10 \mu \mathrm{M}) \mathrm{CCCP}$ in the reaction medium. The DCMU effect on hydrogen evolution and uptake activities (panel B) was conducted on 7 day old culture of Nostoc sp. grown in BG11 ${ }_{0}$ medium. The hydrogen evolution (open circles) and uptake (closed circles) activities of Nostoc sp. were measured as described in Materials and Methods in presence of various concentrations of (0-0.4 $\mu M)$ DCMU in the reaction medium. The hydrogen evolution/uptake ratios (closed triangles) were calculated using the mean values of both activities at each DCMU concentration. Experiments were repeated three times and mean values and standard errors are shown.

Hydrogen and oxygen evolution and uptake activities of Nostoc sp. grown in 2,4-D treated BG11, culture medium:

Enhanced rates of the hydrogen evolution activity of bidirectional hydrogenase was recorded in BG11 $1_{0}$ in Nostoc cells grown cells with increasing Egyptian J. of Phycol. Vol. 11, 2010 
the concentration of 2,4-D. However, uptake hydrogenase exhibited no significant change in response to 2,4-D (Fig. 6A). Both net photosynthetic activity $\left(\mathrm{P}_{\mathrm{N}}\right)$ and true photosynthetic activity $\left(\mathrm{P}_{\mathrm{t}}\right)$ of Nostoc sp. decreased with increasing the 2,4-D concentration in the culture medium (Fig. 6B). In contrast, the rate of Nostoc sp. respiration increased with increasing the 2,4-D concentration in the culture medium (Fig. 6B). 2,4-D decreased $\mathrm{P}_{\mathrm{t}} / \mathrm{R}$ ratio as its concentration was increased. The PSI activity increased in Nostoc grown in 2,4-D treated culture medium (Fig. $6 C)$.
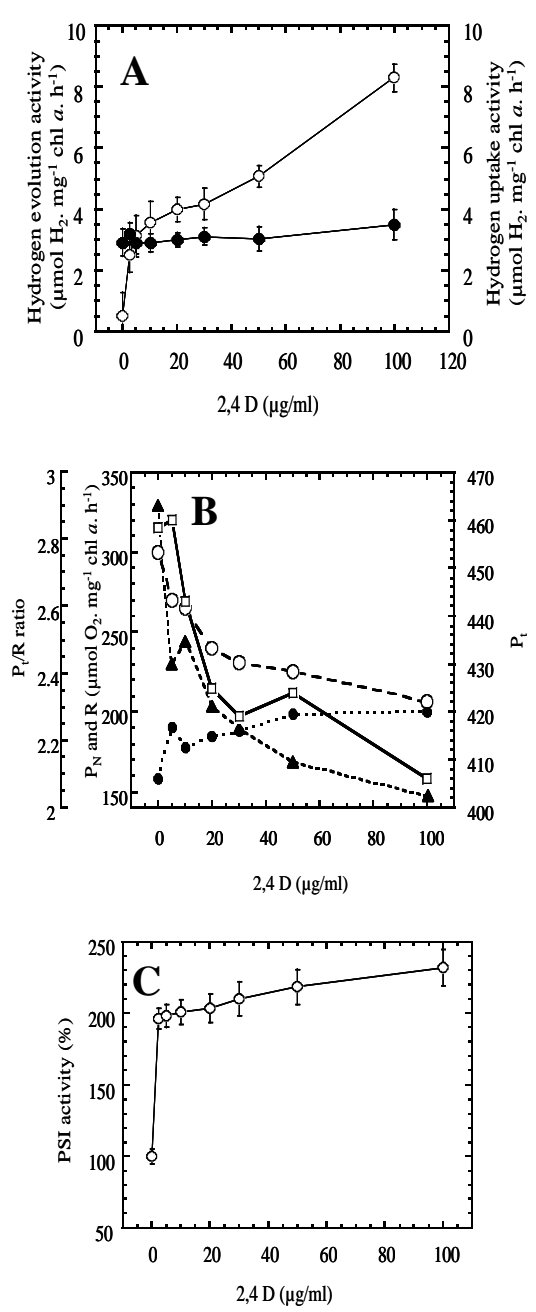

Egyptian J. of Phycol. Vol. 11, 2010
Figure (6): Effect of 2,4-D on hydrogen and oxygen evolution and uptake activities and PSI activity of Nostoc. Hydrogen evolution and uptake activities (Panel A) were measured in Nostoc treated with various concentrations of 2,4D on growth culture. Hydrogen evolution (open circles) and uptake (closed circles) activities were measured on 7 day old culture of Nostoc grown in BG11 $_{0}$ medium with various concentrations of 2,4-D. The effect of 2,4-D on photosynthetic oxygen evolution and respiratory oxygen uptake (Panel B) were measured in Nostoc treated with various concentrations of 2,4-D on growth culture. Net photosynthesis $\left(\mathbf{P}_{\mathrm{N}}\right)$ (open circles) and respiration $(R)$ (closed circles) was measured on 7 day old culture of Nostoc grown in BG11 $_{0}$ medium with various concentrations of 2,4-D. The true photosynthesis (Pt) (open squares) was calculated by the summation of both net photosynthesis and respiration. The photosynthesis/respiration ratio (Pt/R) (closed triangles) were calculated using the mean values of true photosyntheis and respiration at each 2,4$D$ concentration in the culture medium. The effect of 2,4-D on PSI activity of Nostoc (Panel C) was investigated on 7 day old culture of the cyanobacterium grown in BG11 $_{0}$ medium with various concentrations of 2,4-D. Experiments were repeated three times and mean values and standard errors are shown.

-40 - 


\section{Discussion}

Induction and enrichment of heterocysts might be favorable for hydrogen production not only because of their internal nitrogenase/uptake system but might rather due to their role in enhancing oxygen consumption and creating anaerobiosis. Earlier, Tiwari et al. (1981) reported the inductive effect of 2,4-D on heterocyst formation but apart from hydrogenases activity. Here we combined both; heterocyst induction with hydrogenases activity. Furthermore, we are reporting the unusual heterocyst formation in the presence of nitrate, a regular inhibitor of heterocyst formation. The formation of two adjacent heterocysts was rarely observed in 2,4-D treated Nostoc sp. SAG 2306 but never in untreated cultures. The decrease in chl a/dry mass by 2,4-D might be attributed to the increase in heterocysts frequency (heterocysts have lower chl $a$ content but higher dry mass than vegetative cells). 2,4-D recovered the inhibitory effect of up to 90 $\mu \mathrm{M}$ nitrate nitrogen on heterocysts formation. These results suggests that 2,4-D can be used as an artificial inducer/signal for heterocysts formation in Nostoc sp SAG 2306 even in the presence of combined nitrogen. The stimulatory effect of 2,4-D on heterocyst formation could not be recorded in two extreme cases: zero and $\geq 120 \mu \mathrm{M}$ nitrogen. The first because there was no inhibitory effect to overcome (heterocysts already existed) and the latter because the concentration of $120 \mu \mathrm{M}$ nitrogen was too high to overcome its inhibitory action. Despite its inductive role on heterocyst formation, the 2,4-D-induced heterocysts seem fragile and detach from the filament, losing nutrient exchange with vegetative cells and hence function. This phenomenon was also observed in BG11 $1_{0}$ grown Nostoc cells. Such detachment of heterocysts is mostly attributed to aging when the culture reaches a stationary phase of growth and cell division possibly reducing the culture requirement for nitrogen. In this respect, Ning and Xu (2004), Ow et al. (2008) and Cardina et al. (2007) reported detailed studies concerning heterocyst-vegetative cells transitions and interlinks. Maintaining heterocysts attached would be a target of a future study. The increase in growth as a dry mass in 2,4-D-treated cultures of Nostoc sp might be attributed to the increase in heterocysts frequency with their relatively higher dry mass than vegetative cells. 
2,4-D has a stimulating role in vegetative cell transformation into hetrocysts as revealed by the increase in heterocysts frequency.

Reducing oxygen evolution is a prerequisite for increasing the hydrogen productivity because the cyanobacterial hydrogen evolving enzyme systems are highly sensitive to minute concentrations of oxygen. The decrease in photosynthesis/respiration ratio with increasing the 2,4-D concentration reduces the cellular oxygen partial pressure. Photosynthetic control of hydrogen metabolism revealed a strong correlation between $\mathrm{P}_{\mathrm{N}}$ and hydrogen metabolism (Abdel-Basset and Bader, 1997; 1998; 1999; 2008; Abdel-Basset et al., 1998).

The increase in PSI activity in Nostoc sp SAG 2306 treated with 2,4-D possibly leads to an increase in reductant supply for hydrogenases. Since phycobilisomes are the light harvesting complex of PS II in cyanobacteria (Katoh and Gantt, 1979; Himadri and Louis, 1984; Kura-Hotta et al., 1986; Bald et al., 1996), the decrease in photosynthesis of Nostoc sp. treated with 2,4-D might be attributed to the decrease in phycocyanin/chl $a$ ratio indicating a decrease in phycobilisomes content and subsequently a decrease in oxygen evolution occurred. Such decrease in photosynthetic oxygen evolution and phycocyanin/chl $a$ ratio was associated with an increase in hydrogen evolution activity in Nostoc treated with 2,4-D. The investigation of reducing the phycobilisomes content on oxygen and hydrogen evolution in a mutant model cyanobactium with low phycobilisomes content would be of interest in future studies of hydrogen production.

The cyanobacterium under investigation showed a conspicuous activity of both uptake and bidirectional hydrogenases with low $\mathrm{Km}$ values. The two enzymes showed different characteristics in optimum $\mathrm{pH}$, temperature and response to the herbicide and PSII blocker DCMU (3-(3,4-dichlorophenyl)-1,1dimethylurea) and the photosynthetic uncoupler CCCP (carbonyl cyanide mchlorophenylhydrazone). The optimum temperature for hydrogen evolution in Nostoc was between $25-35{ }^{\circ} \mathrm{C}$. In general the optimum temperature for hydrogen 
production for most cyanobacterial species is between $30-40{ }^{\circ} \mathrm{C}$ and varies from species to species of cyanobacteria (Dutta et al., 2005). For example, Nostoc cultured at $22{ }^{\circ} \mathrm{C}$ showed higher rates of hydrogen production than at $32{ }^{\circ} \mathrm{C}$ (Ernst et al., 1979), while Nostoc muscorum SPU004 showed optimum hydrogen production at $40{ }^{\circ} \mathrm{C}$ (Datta et al., 2000). Anabaena variabilis SPU 003 on the other hand show optimum hydrogen production at $30{ }^{\circ} \mathrm{C}$ (Moezelaar and Stal, 1994; Serebryakova et al., 2000).

Although the enrichment of heterocysts would be one of the routes for increasing the hydrogen productivity in heterocysteous cyanobacteria, a serious obstacle remains to overcome in future studies is the detachment of heterocysts from vegetative cells to maintain energy and nutrient exchange between both cells as a gate of hydrogen production.

\section{References}

Abdel-Basset, R. and Bader, K. P. (1997). Characterization of hydrogen photoevolution in Oscillatoria chalybea detected by means of mass spectrometry. Z. Naturforsch., 52c:775-781.

Abdel-Basset, R. and Bader, K. P. (1998). Physiological analyses of hydrogen gas exchange in cyanobacteria. J. Photochem. Photobiol. B: Biology, 43:146-151.

Abdel-Basset, R. and Bader, K. P. (1999). Effects of stress conditions and calcium on the light-induced hydrogen gas exchange in Oscillatoria chalybea. J. Plant Physiol., 155: 86-92.

Abdel-Basset, R. and Bader, K. P. (2008). Hydrogen evolution in relation to PSI-reducible substrates in the cyanobacterium Oscillatoria chalybea assayed by means of mass spectrometry. Int. J. hydrogen ener., 33:2653-2659.

Abdel-Basset, R.; Spiegel, S. and Bader, K. P. (1998). Saturation of cyanobacterial photoevolution of molecular hydrogen by photosynthetic redox components. J. Photochem. Photobiol. B: Biology 47:31-38.

Adams, D. G. (2000) Heterocyst formation in cyanobacteria. Curr. Opin. Microbiol., 3:618-624.

Appel, J. and Schulz, R. (1998). Hydrogen metabolism in organisms with oxygenic photosynthesis: hydrogenases as important regulatory devices for a proper redox poising? J. Photochem. Photobiol. B: Biology B, 47:1-11.

Appel, J., phynpruch, S., Steinmuller, K. and Schulz, R. (2000). The bidirectional hydrogenase of Synechocystis sp. PCC 6803 works as an electron valve during photosynthesis. Arch. Microbiol., 173:333-338. 
Bald, D.; Kruip, J. and Rögner, M. (1996). Supramolecular architecture of cyanobacterial thylakoid membranes: how is the phycobilisome connected with the photosystems? Photosynth. Res., 49:103-118.

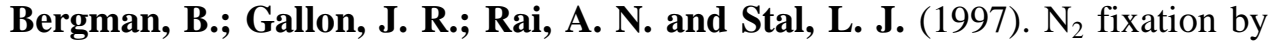
non-heterocystous cyanobacteria. FEMS Microbiol. Rev., 19:139-185.

Böhme, H. (1998). Regulation of nitrogen fixation in heterocyst-forming cyanobacteria. Trends Plant Sci., 3:346-351.

Boison, G.; Bothe, H.; Hansel, A. and Lindblad, P. (1999). Evidence against a common use of the diaphorase subunits by the bidirectional hydrogenase and by the respiratory complex I in cyanobacteria. FEMS Microbiol. Lett., 174:159-165.

Bradford, M. M. (1976). A rapid and sensitive method for the quantitation of microgram quantities of protein utilizing the principle of protein-dye binding. Anal. Biochem., 72:248-254.

Cardonaa, T.; Battchikova, N.; Agervalda, A.; Zhang, P.; Nagel, E.; Aro, E. M.; Styring, S.; Lindblad, P. and Magnusona, A. (2007). Isolation and characterization of thylakoid membranes from the filamentous cyanobacterium Nostoc punctiforme. Physiol. Plant., 131: 622-634.

Carrasco, C. D.; Buettner, J. A. and Golden, J. W. (1995). Programed DNA rearrangment of a cyanobacterial hupL gene in heterocysts. Proc. Natl. Acad. Sci. USA, 92:791-795.

Codd, G. A., Okabe, K. and Stewart, W. D. P. (1980). Cellular compartmentation of photosynthetic and photorespiratory enzymes in the heterocystous cyanobacterium Anabaena cylindrica. Arch. Microbiol., 124:149- 154.

Colbeau, A., Kelly, B.C. and Vignais, P. M. (1980). Hydrogenase activity in Rhodopseudomonas capsulata: relationship with nitrogenase activity. $J$. Bacteriol., 144:141-148.

Curatti, L., Flores, E. and Salerno, G. (2002). Sucrose is involved in the diazotrophic metabolism of the heterocyst- forming cyanobacterium Anabaena sp. FEBS Lett., 513:175-178.

Datta, M., Nikki, G. Shah, V. (2000). Cyanobacterial hydrogen production. World J. Microbiol. Biotechnol., 16: 8-9.

Donze, M., Haveman. J. and Schiereck, P. (1971). Absence of photosystem II in heterocysts of the blue-green alga Anabaena. Biochim. Biophys. Acta., 256:157-161.

Dutta, D., De, D., Chaudhuri, S. and Bhattacharya, S. K. (2005). Hydrogen production by cyanobacteria. Microb. Cell Factor., 4:36-47.

Ernst, A., Kerfin, W., Spiller, H. and Boger, P. (1979). External factors influencing light-induced $\mathrm{H}_{2}$ evolution by the blue-green algae, Nostoc muscorum. Z. Naturforsch., 34:820-825.

Fay, P. (1992). Oxygen relations of nitrogen fixation in cyanobacteria. Microbiol. Rev., 56:340-373.

Flores, E. and Herrero, A. (1994). Molecular evolution and taxonomy of the cyanobacteria, p. 487-517. In D. A. Bryant (ed.), The molecular biology

Egyptian J. of Phycol. Vol. 11, $2010 \quad$ - 44 - 
of cyanobacteria. Kluwer Academic Publishers, Dordrecht, The Netherlands.

Golden, J. W. and Yoon, H. S. (2003). Heterocyst development in Anabaena. Curr. Opin. Microbiol., 6:557-563.

Hansel, A. and Lindblad P. (1998). Towards optimization of cyanobacteria as biotechnologically relevant producers of molecular hydrogen, a clean and renewable energy source. Appl. Microbiol. Biotechnol., 50:153160.

Herrero, A., Muro-Pastor, A. M. and Flores, E. (2001). Nitrogen control in cyanobacteria. J. Bacteriol., 183:411-425.

Himadri, B. P. and Louis, A. S. (1984). A highly active oxygen-evolving photosystem II preparation from the cyanobacterium Anacystis nidulans. Plant Physiol., 74:742-745.

Holden, M. (1976). Chlorophylls. In: Chemistry and biochemistry of plant pigments 2nd Ed. Vol. 2. pp. 1-37, Goodwin, T.W., ed. London: Academic Press.

Houchins, J. P. (1984). The physiology and biochemistry of hydrogen metabolism in cyanobacteria. Biochim. Biophys. Acta, 768:227-255.

Houchins, J. P. and Burris, R. H. (1981). Occurrence and localization of two distinct hydrogenases in the heterocystous cyanobacterium Anabaena sp strain 7120. J. Bacteriol., 146:209-214.

Howarth, D. C. and Codd, G. A. (1985). The uptake and production of molecular hydrogen by unicellular cyanobacteria. J. Gen. Microbiol., 131:1561-1569.

Katoh, T. and Gantt, E. (1979). Photosynthetic vesicles with bound phycobilisomes from Anabaena variabilis. Biochim Biophys Acta (BBA) - Bioenergetics, 546:383-393.

Kulasooriya, S. A. and Fay, P. (1974). On the reversibility of heterocyst differentiation. Europ. J. Phycol., 9:97-100.

Kura-Hotta, M., Satoh, K. and Katoh, S. (1986). Functional linkage between phycobilisome and reaction center in two phycobilisome oxygenevolving photosystem II preparations isolated from the thermophilic cyanobacterium Synechococcus sp. Archiv. Biochem. Biophys., 249:1-7.

Lambert, G. R. and Smith, G. D. (1981). The hydrogen metabolism of cyanobacteria (blue-green algae). Biol. Rev., 56:589-660.

Lindblad P. (1999). Cyanobacterial $\mathrm{H}_{2}$-metabolism: knowledge and potential/ strategies for a photobiotechnological production of $\mathrm{H}_{2}$. Biotecnol. Apl., 16:141-144.

Meeks, J. C. and Elhai, J. (2002). Regulation of cellular differentiation in filamentous cyanobacteria in free-living and plant-associated symbiotic growth states. Microbiol. Mol. Biol. Rev., 66:94-121.

Moezelaar, R. and Stal, L. J. (1994). Fermentation in the unicellular cyanobacterium Microcystis PCC7806. Arch. Microbiol., 162:63-69.

Nicolaisen, K., Hahn, A. and Schleiff, E. (2009). The cell wall in heterocyst formation by Anabaena sp. PCC 7120. J. Basic Microbiol., 49:5-24. 
Ning, D. and Xu, X. (2004). alr0117, a two-component histidine kinase gene, is involved in heterocyst development in Anabaena sp. PCC 7120. Microbiology, 150:447-453.

Ow, S. Y., Cardona, T.; Taton, A.; Magnuson, A.; Lindblad, P.; Stensjö, K. and Wright, P. C. (2008). Quantitative shotgun proteomics of enriched heterocysts from Nostoc sp. PCC 7120 using 8-plex isobaric peptide tags. J. Proteome Res., 7:1615-1628.

Papen, H., Kentemich, T.; Schmülling, T. and Bothe, H. (1986). Hydrogenase activities in cyanobacteria. Biochimie, 68:121-132.

Potts, M., Angeloni, S. V.; Ebel, R. E. and Bassam, D. (1992). Myoglobin in a cyanobacterium. Science, 256:1690-1692.

Rippka, R. and Herdman, M. (1992). Pasteur culture collection of cyanobacteria strains in axenic culture. Vol. 1, Catalogue of strains. 103 P., Institut Pasteur, Paris, France.

Serebryakova, L. T., Sheremetieva, M. E. and Lindblad, P. (2000). $\mathrm{H}_{2}$-uptake and evolution in the unicellular cyanobacterium Chroococcidiopsis thermalis CALU 758. Plant Physiol. Biochem., 38:525-530.

Stal, L. J. and Moezelaar, R. (1997). Fermentation in cyanobacteria. FEMS Microbiol. Rev., 182:1624-1631.

Tamagnini, P.; Axelsson, R.; Lindberg, P.; Oxelfelt, F.; Wünschiers, R. and Lindblad, P. (2002). Hydrogenases and hydrogen metabolism of cyanobacteria. Microbiol. Mol. Biol. Rev., 66:1-20.

Tamagnini, P.; Costa, J. L.; Almeida, L.; Oliveira, M.J.; Salema, R. and Lindblad, P. (2000). Diversity of cyanobacterial hydrogenases, a molecular approach. Curr. Microbiol., 40:356-361.

Tchernov, A. A.; Minkova, K. M.; Houbavenska, N. B. and Kovacheva, N. G. (1999). Purification of phycobiliproteins from Nostoc sp. by aminohexyl-sepharose chromatography. J. Biotechnol., 69:69-73.

Tiwari, D. N.; Pandey, A. K. and Mishra, A. K. (1981). Action of 2,4dichloroacetic acid and rifampicin on heterocyst differentiation in the blue-green alga, Nostoc linckia. J. Biosci., 3:33-39.

Troshina, O. Y.; Serebryakova, L. T. and Lindblad, P. (1996). Induction of $\mathrm{H}_{2}$-uptake and nitrogenase activities in the cyanobacterium Anabaena variabilis ATCC 29413: Effects of hydrogen and organic substrate. Current Microbiol., 33:11-15.

Tsygankov, A. A. (2007). Nitrogen-fixing cyanobacteria: A Review. Applied Biochem. Microbiol., 43:250-259.

Wolk, C. P. (1996). Heterocyst formation. Annual Rev. Genet., 30:59-78.

Wolk, C. P. (2000). Heterocyst formation in Anabaena. In Prokaryotic Development. Edited by Shimkets LJ. Washington DC: American Society for Microbiology; p.83-104.

Wolk, C. P., Ernst, A. and Elhai, J. (1994). Heterocyst metabolism and development. In The Molecular Biology of Cyanobacteria. Edited by Bryant DA. Dordrecht: Kluwer Academic Publishers p.769-823.

Yoon, H. S. and Golden, J. W. (1998). Heterocyst pattern formation controlled by a diffusible peptide. Science, 282:935-938.

Egyptian J. of Phycol. Vol. 11, $2010 \quad$ - 46 - 
Yoon, H.S. and Golden, J. W. (2001). PatS and products of nitrogen fixation control heterocyst pattern. J. Bacteriol., 183:2605-2613.

Yoshino, F., Ikeda, H., Masukawa, H. and Sakurai, H. (2007). High photobiological hydrogen production activity of a nostoc sp. Pcc 7422 uptake hydrogenase-deficient mutant with high nitrogenase activity. Marine Biotechnol., 9:101-112.

Yu, L. and Wolin, M. J. (1969). Hydrogenase measurement with photochemically reduced methyl viologen. J. Bacteriol., 98:51-55.

Zhang, C., Sophie, L., Samer, S.; Ling, P. and Sylvie, B. (2006). Heterocyst differentiation and pattern formation in cyanobacteria: a chorus of signals. Molecular Microbiol., 59:367-375. 


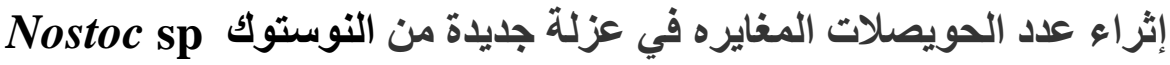

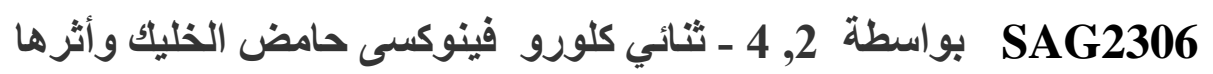
اللاحق على تغيير نسبة التمثيل الضوئي / التنفس وأنشطة انزيمات الهيارورجينيز.

\author{
فتحى محمد مرسى ، امانى حامد ، رفعت عبدالباسط \\ قسم النبات ، كلبه العلوم ، جامعه اسيوط
}

الحويصلات المغايره هي خلايا متخصصه لتنبيت النيتروجين وتوجد فى بعض انولئه انواع البكتيريا

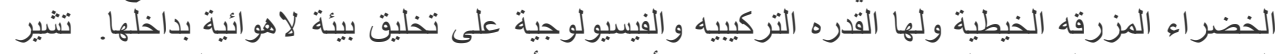

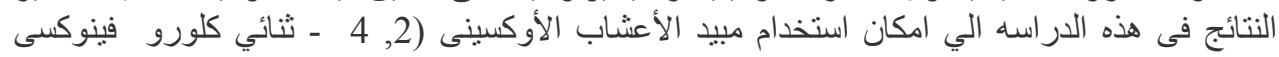

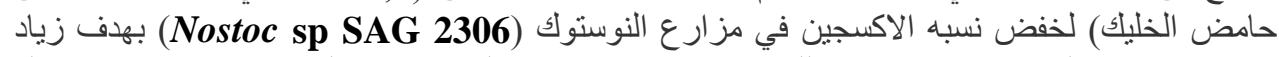

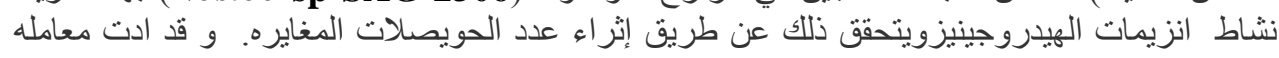

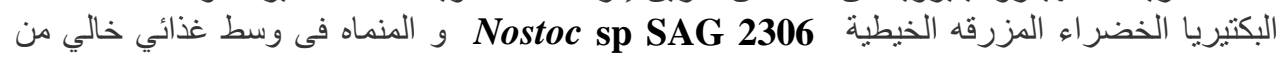

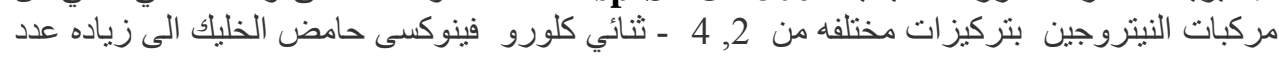

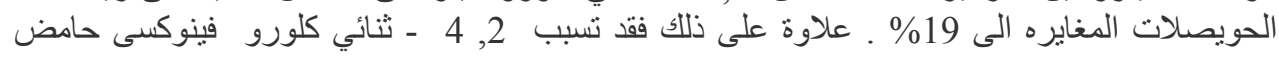

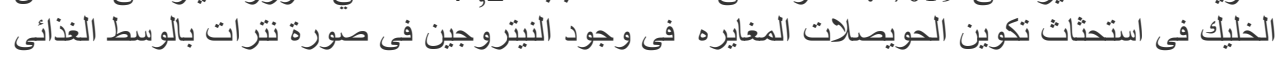

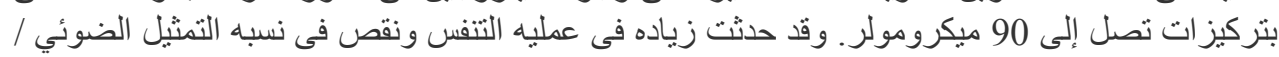

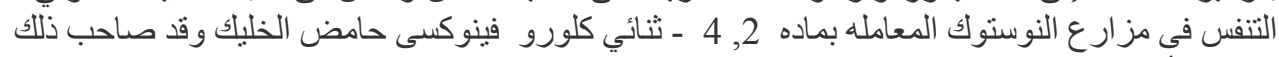

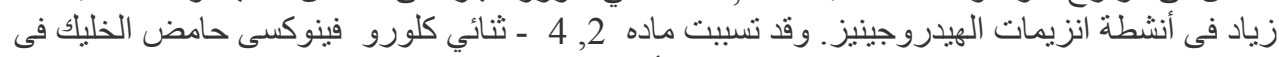

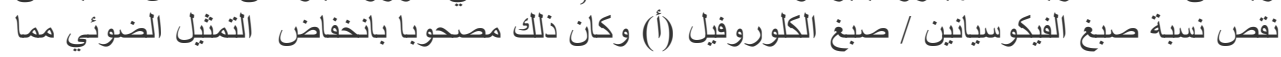

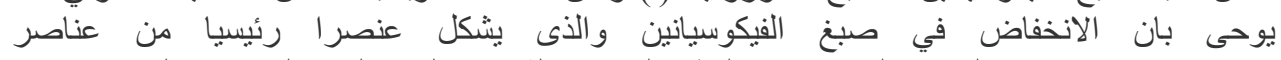

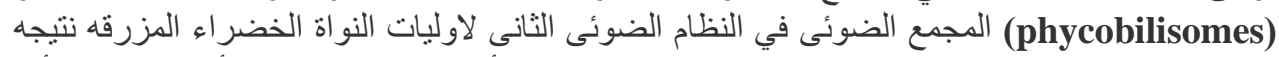

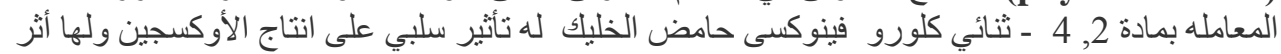

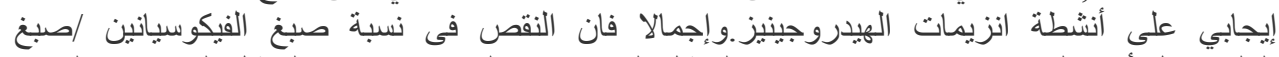

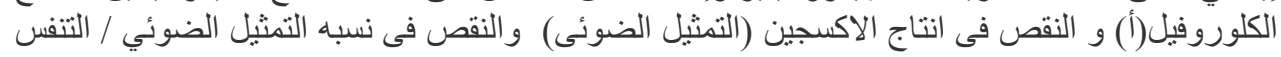

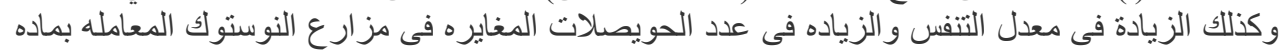

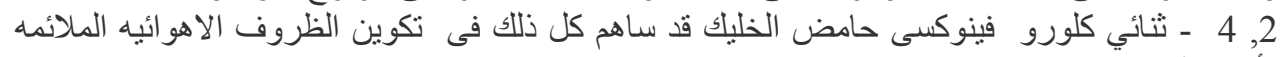
لأيض الهيدروجين. 